\title{
Incubators for innovators
}

\author{
Lynn Kirkpatrick
}

There are many points to consider when deciding whether to locate your business in an incubator.

A

$s$ a life science entrepreneur who has led startups in several different locations, I have experience in many unique incubator settings. I left an academic career in which I had achieved tenure and full professorship of chemistry and biochemistry to cofound an oncology company, ProlX Pharmaceuticals, in Pittsburgh. While CEO there, I brought three drugs from discovery into phase 2 trials, at which point our company merged with Biomira, a larger public vaccine company based in Edmonton, Canada. I worked two years as CSO in the newly merged entity before leaving to start another oncology firm, PHusis Therapeutics, first based in Houston and later in San Diego. Each new stop meant finding a place to call home for my startup. This is never easy, but with proper planning and knowledge, it can be done with minimal chaos.

Through all the stages with ProlX and PHusis (Box 1), I've had homes with various types of services, leasing terms and lab conditions; I've learned the pros and cons of each. In the following article, I describe some of the different types of incubators available to life science ventures and discuss some of the issues you should consider when setting up your company in a new location.

\section{Should you incubate?}

When launching a company, an entrepreneur needs to decide how much they want to do on their own and what they are willing to pay for. In the case of ProlX, I quickly found that simply locating in my own stand-alone space took substantial effort, both in trying to find an appropriate home and then outfitting it to facilitate drug development activities. It was exhausting but exhilarating.

My second startup (Box 1), PHusis, was founded in an incubator and thus took less initial effort, but the level of services at each

Lynn Kirkpatrick is president and CEO of PHusis Therapeutics, San Diego, California, USA.

e-mail:lkirkpatrick@phusistherapeutics.com.

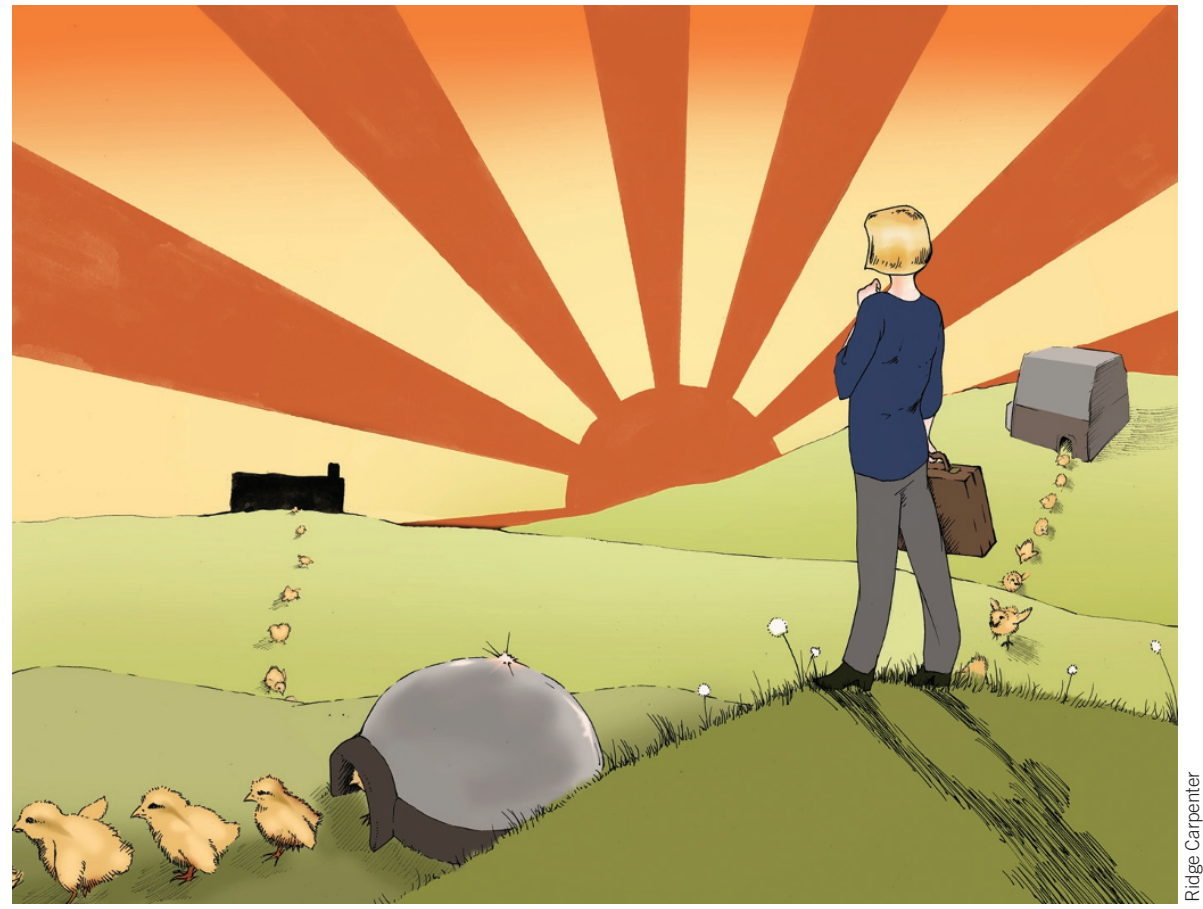

incubator thereafter has varied greatly. This illustrates that you need to consider not only whether you want to be in an incubator at all but also, if you do, what kind. Before you start seeking a location for your company, be prepared to answer these questions:

- How much space do you need now, and how much will you need in a year or two?

- What facilities and equipment do you need-will an office be enough, or do you need wet lab space for bench research?

- Who will provide your startup with internet and phone service?

- How do you handle document and data storage from each employee computer?

- Do you need power backup for incubators, refrigerators or freezers?

The first question can be tricky. Most early stage life science companies initially require just a small amount of room to conduct studies needed for proof of principle; once they attract an investor, they can expand their operations. So the question of how much space to lease initially should be dictated not only by cost but also by growth projections. It is usually true that the best financial terms are obtained through longer leases; however, this can lock you into a space that becomes unsuitable if you need to expand or contract.

These decisions can be easier to make in an incubator, which will often have flexible lease terms. This eliminates the guesswork of whether to commit to a multiyear lease. Although it is difficult to put a dollar amount on various leases in the many incubator locations around the country, monthly costs can range from a few thousand dollars per month for shared space to hundreds of dollars per square foot on an annual basis.

Once you have secured space, the second question comes into play. Securing furnishings 


\section{Box 1 Finding a home}

My first startup, ProlX Pharmaceuticals, was initially located in a medical office building in Pittsburgh. It had limited lab space that we shared with another company. Although this may sound awkward, in the early days of the company's development it proved to be an ideal relationship for us. The arrangement saved on costs and provided some shared equipment that allowed us to get started with some research activities very quickly. However, once we began to get up to full capacity, we needed more physical lab space, and I went on the hunt. I was able to secure additional space in the same building, which meant we didn't need to break our lease to grow.

When I relocated for personal reasons to Tucson, Arizona, I was not in a biotech hub and struggled to find quality lab space. After extensive searching, the company moved into an old bakery that had been renovated to house a data company. Our new space was in a trendy neighborhood and large enough, but it had little wet lab space-although we were able to retrofit it and made it functional. After ProlX was acquired, I started my next company, PHusis Therapeutics, in Houston. I established it in a recently initiated Biotechnology Commercialization Center biotech incubator in The University of Texas Health Science Center that had a fully functional wet lab space, limited used equipment (e.g., refrigerators and freezers, biohazard hoods, incubators and centrifuges) and a suite of offices with furniture. I have since relocated this company to California. My current home for PHusis is in the JLABS incubator in San Diego.

and capital equipment (whether new or used) add to your monthly burn rate. Purchasing even the basics can add up to hundreds of thousands of dollars-a difficult outlay when you only have limited funds from the startup founders. For ProlX, I outfitted the company by going to used furniture outlets for desks, chairs and file cabinets. Even that route can run up to tens of thousands of dollars, and that doesn't include computers for employees, equipment required for a wet lab, which means water, sinks, benches and the ability to handle supply shipping and receiving. Will your company be doing tissue culture? Then you'll need purified water systems, which, with installation, can run more than $\$ 10,000$, not including the cost of filters.

It's easy to see how the bills add up. Other creeping costs can include facility maintenance, utilities, cleaning and waste disposal, each of which can add \$200-500 per month. Some of the extra costs my companies have incurred include fixing refrigerators, freezers and cold rooms; biosafety hood repair and certification; and centrifuge, autoclave and lyophilizer repair. Each can range from $\$ 1,500$ to $\$ 4,000$. A simple plumbing fix can cost you nearly $\$ 200$ per hour in some locations.

Committing to a lease and managing these costs pose all kinds of hurdles, financial and otherwise. However, many of these challenges are minimized when you establish your company in an incubator. Your monthly rent will cover many services provided by the incubator (your lease will list the details). An incubator might also provide furniture and some basic lab equipment, and sometimes support staff to deal with plumbing and electrical problems or a leaky roof. I've had to deal with all three of those issues in a stand-alone space, and I had to cover the costs. It all takes time away from growing the business.

Question three in the above list seems simple, but in the stand-alone locations I've inhabited, I spent an enormous amount of time just keeping the internet running. This infrastructure is often taken for granted when in an academic setting or working for a larger company, but when you are on your own and the internet fails, reality quickly sets in. It certainly helps if you have an employee with technical savvy; at ProlX I was fortunate to have a go-to person that I could rely on, but you might not be so lucky. At PHusis (before Johnson \& Johnson Innovation's JLABS), I eventually opted for a service provider because I spent too much time 'troubleshooting' our internet connection. Even so, I recently experienced poor computer performance and found I had over 200 updates that needed to be manually installed.

Question four deals with whether to house your own server to handle document storage and backup or to rely on outside services. The situation has changed over the last decade as there are now a multitude of document storage service providers that facilitate document sharing. These can range from having a simple Dropbox account to more sophisticated cloudbased 'vaults' that aid in tracking the documents that are uploaded or viewed by the team or outside parties (such as SecureDocs for more corporate document sharing and Collaborative Drug Discovery, which aids in basic data storage and evaluation).

Once those questions are answered, you can move on to the last one on the list. How do you handle power outages, especially if you have highly valuable cell lines in incubators or other items in refrigerators and freezers? Usually in a stand-alone space you are on your own; in the two incubators I used for PHusis, the backup power was handled by the facility, each in a somewhat different manner. One incubator identified for me the power outlets that were linked to backup generators so I could ensure that my refrigeration units and incubators were protected from outages. The other had its own backup for the entire facility, which removed that worry entirely.

\section{Know your incubator}

In my experience, life in an incubator is a lot easier for the entrepreneur-as it should be. These places are set up to help startups thrive, after all. The good news is that today the life science startup ecosystem has expanded, and incubators are popping up all over. In the past few years, more than 100 incubators have been established in the United States, offering varying degrees of resources, administrative and facility support, mentorship, funding and education. Many of these incubators are associated with universities or medical centers and are set up by the state or, more recently, by big pharma, as with Bayer's CoLaborator and Johnson \& Johnson Innovation's JLABS (Table 1). All of these groups run their facilities based on different models that I loosely categorize into three groups.

Management-services model. Many life science entrepreneurs have potentially game-changing scientific expertise but lack experience in and knowledge of what it takes to set up and run a company. The management-services model incubator, also called an accelerator, aims to help entrepreneurs build their business skills, providing space along with shared office services and a team of business development experts. These experts may help with the incorporation procedure, business plan preparation, financial planning, human resources and intellectual property services. (The biggest advantages here are for scientists embarking on their first company rather than for serial entrepreneurs. For experienced entrepreneurs, the cost for participating in such facilities, which include not only the base rent but also usually fees for services that you may not use, may outweigh its rewards.)

For new entrepreneurs, this business assistance and intense training program can be highly valuable. By offering shared services, high-quality business expertise is provided at a reasonable cost compared with rates for outside consultancies. A management-services incubator may also aid the company in securing capital; a few incubators of this type actually undertake investments themselves in the companies they accept into their facility. Two examples here are 
Table 1 Select pharmaceutical, state or privately operated incubators

Incubator. Location(s) (URL)

Operator

Alexandria. Seattle; San Francisco; San Diego; Boston; New York; Rockville and Gaithersburg, Maryland; and Research Private

Triangle Park, North Carolina (http://www.are.com/)

Bayer's CoLaborator. San Francisco (http://www.colaborator.bayer.com/)

Life Sciences Greenhouse of Central Pennsylvania. Harrisburg (http://www.Isgpa.com/)

Central Valley Business Incubator. Fresno, California (http://cvbi.org/about/)

Bioscience Park Center. Aurora, Colorado (http://fitzscience.org/work/bioscience-park-center/)

CURE Innovation Commons. Groton, Connecticut (not yet open) (http://cureconnect.org/cure-innovation-commons/)

Johnson \& Johnson Innovation's JLABS. San Francisco, Boston, Houston and San Diego (https://www.janssenlabs.com/)

Kansas Bioscience Authority. Olathe (http://www. kansasbioauthority.org/)

Long Island High Technology Incubator. Stony Brook, New York (http://www.lihti.org/)

BioMaryland Center. Rockville and Baltimore (http://bio.maryland.gov/resources/pages/incubators-research-parks.aspx)

Michigan Life Science and Innovation Center. Plymouth (http://www.mlsic.com/)

North Carolina Biotechnology Center. Research Triangle Park

(http://directory.ncbiotech.org/support-categories/business-incubator)

New Orleans Biolnnovation Center (http://www.neworleansbio.com/)

Pittsburgh Life Sciences Greenhouse (http://www.plsg.com/business-growth-programs/executive-program/)

QB3@953. San Francisco (http://www.qb3.org/startups/incubators/953)

Rochester BioVenture Center. New York (http://www.rochesterbioventure.org/)

UTH Biotechnology Commercialization Center. Houston

(https://www.uth.edu/otm/bcc-biotechnology-commercialization-center/)

Virginia Biosciences Commercialization Center. Richmond

(http://vabiotech.com/commercialization/virginia-biosciences-commercialization-center/)

Source: Refs. 2-5; http://www.techmanage.net/resources/?category=14; http://www.masslifesciences.com/why-ma/incubators/.

\section{Type of facility}

Leased space

Pharmaceutical Limited turnkey

State Management services

State Management services

State Leased space

Pharma Leased space

Turnkey

Management services

State

State

Leased space

Management services

Management services

State

State

Management services

State

Management services

State

Private

Management services

State

State

Management services

Leased space

Leased space

State

Leased space the Kansas Bioscience Authority in Olathe and the Blueprint Health Accelerator in New York.

Leased space with core facilities but limited equipment. This incubator model offers leased office and wet lab space along with lab furniture and limited equipment. The equipment may be for common use by all tenants or provided on a first-come, first-served basis. The incubator might offer conference rooms, core scientific facilities such as those found in an academic setting, and support staff to maintain the facility, which eliminates the concern for the entrepreneur. In this incubator model, the tenant may still be responsible for dealing with telephone and data services, shipping and receiving, and other waste disposal and supply management.
The University of Texas Health Science Center at Houston uses this model in their Biotechnology Commercialization Center, which provides office and wet lab space and access to both University of Texas Health Science Center core facilities and a limited amount of used equipment.

With the reduction in costs for equipping and furnishing the space, this incubator model is a helpful launching pad for new companies. It is, however, the lessee's responsibility to maintain any equipment provided, and for used equipment that can become a substantial cost burden. For example, sophisticated analytical equipment can have service fees starting at $\$ 5,000$ and software costs of more than $\$ 15,000$. I had the unfortunate situation of having to purchase

\section{Box 2 In the lab of luxury}

JLABS offers on-site education for entrepreneurs, with topics ranging from the business fundamentals - creating a cap table or negotiating a term sheet- to more sophisticated topics, such as forming a regulatory strategy or filing an investigational new drug (IND) application. Resident entrepreneurs are also connected with resources in the life sciences industry, including potential investors ranging from traditional venture capitalists to angels and grant agencies, as well as Johnson \& Johnson's internal R\&D, deal-making and corporate venture teams.

These resources allowed me to integrate smoothly into the local, thriving life science culture in San Diego. The networking sessions helped me with hiring, as word of mouth provided names of skilled individuals. Other business development sessions also acquainted me with local industry leaders, service providers and many other resources that I would not have been immediately aware of in a stand-alone setting. Additionally, the exposure we received as being part of JLABS aided me in my business development activities.

the operating software for a spectrophotometer that could not be returned even after we found the instrument had a mortal wound. After the software investment, we still had to purchase a new instrument.

Turnkey leased space. The turnkey incubator model provides the true quick-start approach to becoming an entrepreneur. It may or may not provide business experts to help with the management services, but all the tools an entrepreneur needs, outside of perhaps highly specialized lab equipment, are provided with a multitude of support services. With building security and safety standard operating procedure, waste disposal, shipping and receiving, postal, telephone and data support all provided, the entrepreneur can be freed up to focus on scientific endeavors.

This model offers use of common equipment and other shared facilities, which means each lessee has a smaller footprint. Because of this, on a per-square-foot basis, the rent in the turnkey model may appear higher than that for similar spaces. As an example, you could pay $\$ 250$ per square foot on an annual basis for a small footprint but with additional common space and a fully staffed facility, versus $\$ 45$ per square foot for a larger, wholly contained space that you would have to service yourself, with additional recurring monthly expenses for utilities and maintenance. That lower price per square foot looks inviting, but if you take into account the time required to be move-in ready and the total 
monthly costs to have a space that allows you to immediately begin work, a turnkey operation may end up being the more cost-effective approach. This incubator model may also provide the lessee with connections to R\&D partners and general business services. Ideally the incubator would allow short-term leases, giving you the ability to expand and contract when necessary. My current company is in JLABS in San Diego, which follows this last model. After personally participating in all but the management-services model, I am especially struck by how a fully supported facility has eliminated my need to worry about incidentals and enabled me to focus on the science and business. It has been a breath of fresh air to work in an incubator that has a clear understanding of the issues specifically related to life science entrepreneurship. For example, recognizing that space requirements quickly change with biotechs, JLABS eliminated long-term leases-it has turnkey operations with recurring 90-day lease terms. This allows a company to expand or reduce space more readily than if it were locked into multiyear leases.

The full-service incubator has been a great advantage for PHusis at our current stage of development. In addition to an administrative staff that handles permits, safety and environmental waste handling, there is an on-site educational curriculum (Box 2).

\section{The question of equity}

Several incubator facilities require an equity percentage from the startup in exchange for either services or the right to join the incubator. Giving up this slice may reduce your initial cost of getting off the ground, but these new shareholders might play more of a role than you anticipated if you're faced with an acquisition or merger. Thus, you need to be sure you are getting the appropriate value for any equity you give up, and that value can be in the form of access to highly skilled intellectual property or individuals associated with an incubator. It can also be through future financing opportunities.

That being said, first-time founders may find that parting with equity is immensely valuable if the incubator offers business coaching and networking along with the other support services. Would $5 \%$ equity in your company be a good exchange for getting business and legal expertise that would allow you to focus on developing the technology and maximizing your company's potential? It's a tough question; often it's a reasonable proposition for an initial startup but not for a more established company with higher valuation.

Giving up equity may also bring in funding of course, and can include an option for the incubator to acquire or license your technology. If the option is not executed and the decision is made by the investor not to acquire the technology, the company is free to proceed on its own. This can be viewed as a positive thing-freedom to operate as you please. However, returned rights may also taint the technology in the eyes of other prospective investors or partners. There are also questions around whether equity ownership by a university or pharmaceutical company might hamper other investments or collaborations. Each scenario brings benefits and potential consequences and should be fully considered before parting with equity in exchange for incubator space. The correct answer will vary by company situation and stage.

Rental rates or equity slices, in my experience, vary depending on the location of the facility. Many rents will be based on the market rates in the particular area, especially if it's a state institution. Equity slices will depend on what is being provided (or what is perceived to be provided) by the landlord.

\section{Make the most of your incubator}

Over the past ten years, more pharmaceutical companies have entered the life science incubator arena, realizing that innovation exists outside their doors and they need to foster it. But plenty of incubators have been launched by state organizations, universities and regional enterprise centers, both in and outside biotech hubs. Life science magazine The Scientist reported in 2014 that the number of new business incubators around the country has increased-from dozens in the 1980 s to 1,250 in 2012-as economic developers realize the opportunity, especially following mass layoffs at pharmaceutical companies $^{1}$. It is difficult to provide cost comparisons between the various types, but many state-run incubators are limited in the rates they charge by the fair market rents in their areas. Other facilities that are subsidized by regional economic development funds may provide their services below fair market value with the understanding that the subsidized investment is returned in local job growth.

These new facilities, like EnterpriseWorks Chicago, the Helix Center Biotech Incubator in
St. Louis, and the New Orleans BioInnovation Center (NOBIC), were established to not only aid the development of academic innovation but also revitalize the community's economy. EnterpriseWorks Chicago offers cheap rent to entrepreneurs, with shared office renting for $\$ 100$ a month and shared lab space at an additional $\$ 600$. NOBIC also provides low or no-cost services, such as business planning, intellectual property assistance, fundraising advice, educational round table conversations and seminars, and it even has a BioFund loan system for its clients.

There is a final advantage incubators offer. It comes in the form of intangibles, such as educational seminars or access to speakers visiting the incubator or university. It comes from the exposure to potential partners and investors, or simply from the camaraderie of other scientists nearby, and the ability to discuss methodologies or borrow supplies in emergency situations. Networking is a big part of growing a life science company, and incubators can provide many avenues for this. The fact that in an incubator there are resources to query, warm bodies around and people with which to network might appeal to you. With luck, you may find a quick path to progress and future financing, and will ultimately graduate into your own individual leased space.

\section{COMPETING FINANCIAL INTERESTS}

The author declares no competing financial interests.

1. Grens, K. Incubator boom. The Scientist (1 March 2014).

2. Anonymous. 34 biotech and pharma incubators find out where life science innovations are hatched. Genet. Eng. Biotechnol. News (21 April 2014).

3. Hernandez Sherwood, C. Funding sources for life science startups. eMed, http://www.entrepreneurship.org/ emed/funding-sources-for-life-science-startups.aspx (2013).

4. Hernandez Sherwood, C. What are some of the lead ing life science incubators? eMed, http://www.entrepreneurship.org/emed/emed-blog/2014/august/ what-are-some-of-the-leading-life-science-incubators. aspx (2014).

5. Anonymous. Florida's business incubators. Business Florida, http:/www.floridatrend.com/article/14680/ business-florida-2013--business-incubators (2013).

\section{First Rounders Podcast:}

\section{Carl Feldbaum}

Carl Feldbaum was the founding president of the Biotechnology Industry Organization (BIO), and he is the current chairman of the Life Sciences Foundation. His podcast conversation with Nature Biotechnology touches on his assistance in prosecuting Watergate, his visit to Saddam Hussein's palace and how he built BIO from the ground up (http://www. nature.com/nbt/podcast/index.html).

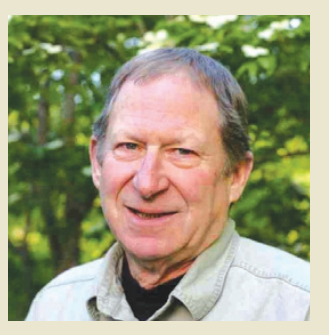

